\title{
Crescimento e inflação na Argentina nos governos Kirchner
}

PIERRE SALAMA

$\mathrm{D}$ ESDE 2003, a Argentina voltou a apresentar uma industrialização sólida e um crescimento elevado. Embora insuficiente, por permanecerem fortes as pressões exercidas sobre as capacidades de produção instaladas, a taxa de investimento aumentou. As despesas sociais e assistenciais cresceram, sem afetar os grandes equilíbrios macroeconômicos, com exceção, notável, aliás, da alta acelerada dos preços. A distribuição da renda tornou-se menos desigual. A pobreza recuou muito. Segundo a Cepal, diminuíram tanto a profundidade da pobreza quanto as desigualdades entre os pobres: um balanço econômico e social globalmente bom, apesar de importantes riscos inflacionistas e problemas de governança.

A retomada extremamente vigorosa da economia explica-se, em primeiro lugar, pelo abandono da política de taxa de câmbio real apreciada dos anos 1990. Com a forte desvalorização do peso, no fim de 2001, e o abandono consecutivo do Plano de conversibilidade, que estabelecia uma paridade nominal entre o peso e o dólar, a Argentina mergulhou numa crise muito forte. Mas, desde 2003, o setor industrial, protegido pela taxa de câmbio, conheceu um forte crescimento. O novo despertar da economia levou a um aumento do número de empregos e da massa salarial, apesar da redução, produzida pela crise, dos salários reais. Em seguida, a revalorização dos salários e o número maior de empregos, ${ }^{1}$ que favorecem o aumento do consumo, vão "puxar" o crescimento. A alta dos lucros e das perspectivas de valorização do capital conduzem à alta relativa dos investimentos, ${ }^{2}$ a qual, junto com o aumento das despesas públicas, alimenta o crescimento. Um círculo virtuoso se instala com grande facilidade, mesmo porque a restrição externa desaparece, especialmente graças à explosão do preço das commodities, assim como à alta das exportações de produtos industrializados. Quanto à restrição orçamentária, por sua vez, ela desaparece graças às arrecadações fiscais provenientes, por um lado, do crescimento, e por outro lado, do maior peso da pressão fiscal.

Esse círculo virtuoso, entretanto, é ameaçado por uma nova e forte onda inflacionista e corre o risco de tornar-se um círculo vicioso. Desde 2007, a alta da taxa de inflação é patente, apesar das manipulações do índice dos preços. ${ }^{3}$ Dessa forma, a alta do poder aquisitivo dos assalariados fica abaixo daquilo que 
resulta das estatísticas oficiais, a revalorização da taxa de câmbio em termos reais é superior à anunciada e a competitividade das exportações de manufaturados está enfraquecida. Será sustentável o modelo argentino "salvo" pela soja? O risco inflacionista e a perda de competitividade da indústria são reais. Nesse ponto, o modelo de desenvolvimento que se seguiu ao fracasso do plano de conversibilidade encontra limitações. Depois das eleições presidenciais de outubro de 2011, o novo governo se encontrará diante da seguinte alternativa: aprofundar o modelo, prosseguindo numa política social mais "generosa" e numa taxa de câmbio depreciada, esperando que a intensificação dos investimentos, encorajada por uma política industrial mais audaciosa, reduza a taxa da inflação; ou, o que parece mais provável, procurar conter o risco inflacionista por um controle maior da demanda global, com o risco de frear a alta dos salários e as despesas sociais, e deixando a taxa de câmbio valorizar-se. O propósito deste artigo é tratar da originalidade desse modelo, de seus sucessos e limitações, no que diz respeito, essencialmente, a três pontos: a distribuição da renda, a inflação e a competitividade industrial.

Quadro 1 - Dados estatísticos da Argentina

\begin{tabular}{l|c|c|c|c|c|c|c|c|c|c}
\hline & 2002 & 2003 & 2004 & 2005 & 2006 & 2007 & 2008 & 2009 & 2010 & $2011^{*}$ \\
\hline $\begin{array}{l}\text { Taxa de } \\
\text { crescimento } \\
\text { do PIB }\end{array}$ & -10.9 & 8.8 & 9 & 9.2 & 8.5 & 8.7 & 6.8 & 0.9 & 9 & $6^{*}$ \\
\hline $\begin{array}{l}\text { Inflação** } \\
\text { Taxa de } \\
\text { investimento }\end{array}$ & 12.5 & 14.1 & 18.7 & 20.8 & 23.0 & 24.1 & 25.2 & 21.2 & 24.5 & 24.4 \\
\hline
\end{tabular}

Fonte: Anuário Estatístico da Cepal de 2010 para 2011, previsões (**) do FMI (abril de 2011) Global Economic Outlook. * Previsão. ** Os dados para a inflação estando subestimados desde 2007, os que apresentamos aqui são oficiosos e estimados a partir dos índices provinciais.

\section{A distribuição pessoal da renda menos desigual a partir de 2003}

No terceiro trimestre de 2003, no momento em que o presidente Nestor Kirchner chega ao poder, os $10 \%$ mais ricos da população monopolizavam 39,3\% da renda nacional e, para os $10 \%$ mais pobres, só sobravam $0,7 \%$. Um ano antes do término da presidência de Kirchner, no terceiro semestre de 2010, a parte da renda atribuída aos 10\% mais pobres da população dobrou. Segundo o Indec, o ratio da renda das pessoas proveniente do emprego principal entre os $90 \%$ mais ricos e os $10 \%$ mais pobres passou de 10 no quarto trimestre de 2003 para $8,3 \%$ no quarto semestre de 2010, e, entre as mesmas datas, o Gini diminuiu, passando de 0,471 para 0,390. Quando se reúne o conjunto das fontes de renda, e não mais a renda proveniente do emprego principal, o primeiro ratio passa de 9,7 para 7,7, e o Gini de 0,525 para 0,439 (Indec, 2011). Portanto, a redução das desigualdades é inegável. Ela é da ordem de 18\% durante o período, mesmo com 
uma curta fase de aumento das desigualdades no segundo semestre de 2010, aumento ligado à crise de 2009 e aos efeitos da inflação. No entanto, a redução das desigualdades se mostra mais lenta. De fato, há uma subestimação oficial da alta da taxa de inflação desde a metade de 2007, e a aceleração da alta dos preços atinge mais diretamente o poder aquisitivo das categorias mais pobres.

Embora menores hoje do que em 2003, as desigualdades permanecem extremamente acentuadas. Os $10 \%$ mais pobres da população ganham em média 216 pesos por pessoa mensalmente, ou seja, ao todo, $1,4 \%$ da renda nacional, enquanto os $10 \%$ mais ricos ganham 7.845 pesos, ou seja, um total de $32,89 \%$ da renda nacional, o dobro daquilo que ganham os $10 \%$ que os precedem.

\section{Evoluções fortemente contrastadas do salário real}

\section{e da produtividade do trabalho em periodo longo}

Para compreender as evoluções recentes dos salários reais, é preciso inscrevê-las num período longo. Três tipos de análise podem ser feitos: o primeiro diz respeito à evolução do salário real; o segundo é o da produtividade do trabalho; e, finalmente, o terceiro, o diferencial de taxa de crescimento entre essas duas variáveis.

Há uma volatilidade muito grande do salário real num longo período. Desde 1975, o salário real flutua fortemente em torno de um trend baixista, como se pode verificar no Gráfico 1.

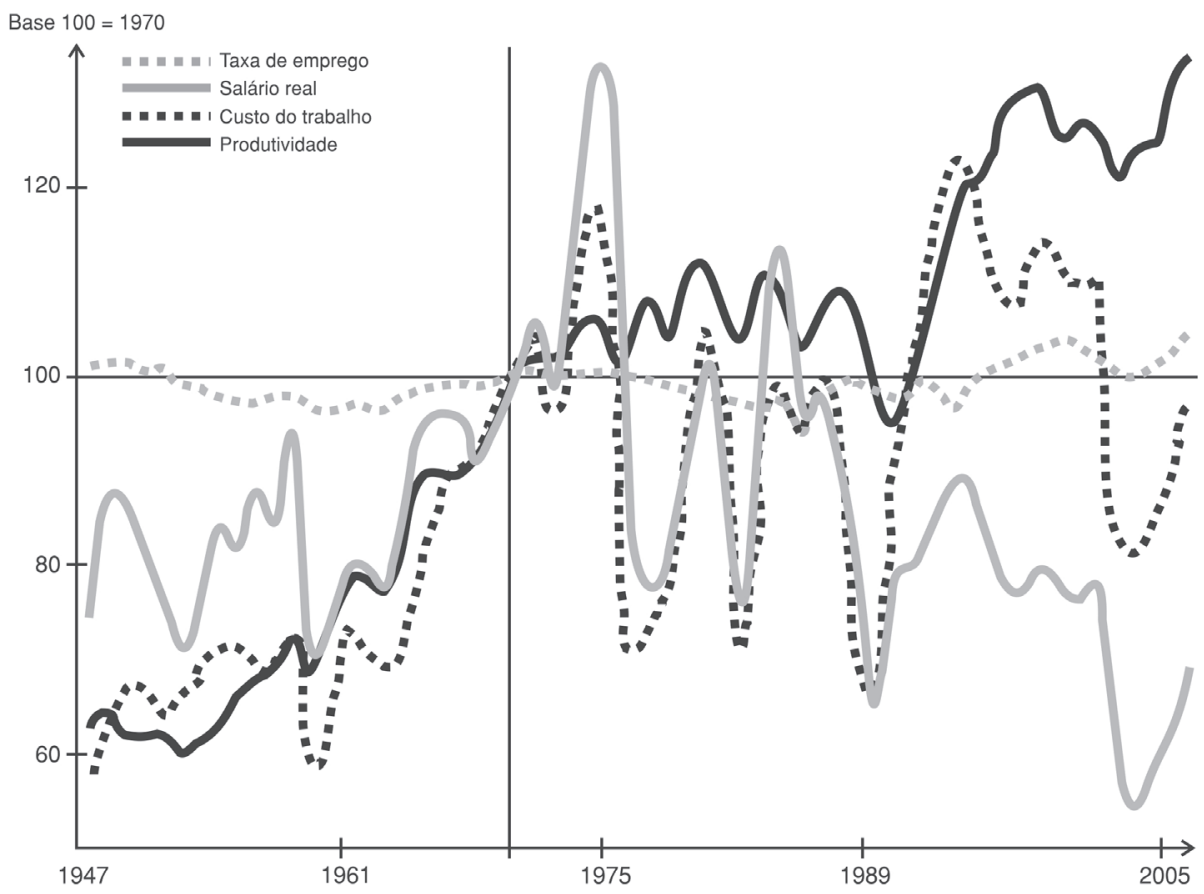

Fonte: Elaborado por Lindenboim et al. (2010), a partir dos dados do Indec, p.548.

Gráfico l - Evoluções da taxa de assalariamento, de salário real, do custo do trabalho e da produtividade média em período longo 1947-2006 (base 100:1970). 
De 1976 a 2003, a tendência do salário real é para a baixa. Na época, a volatilidade dos salários é muito acentuada; o índice do salário real passa de 132 em 1975 (pico) para 78 em 1977. Depois de novas flutuações, atinge o índice 110 em 1984 para cair novamente e chegar em 1989 (ponto mais baixo) a um índice de 65. Desde 2003, o salário real progride e reencontra, em 2006, o nível alcançado no fim dos anos 1950.

A amplitude das flutuações do salário real é considerável, enquanto a da produtividade é muito mais fraca. Depois de numerosas oscilações, a produtividade do trabalho reencontra em 1983 seu nível de 1976, sofre nova queda em 1988 para subir de novo em 1989 ao nível alcançado em 1970. Em comparação com a maior parte dos outros países, onde o crescimento da produtividade é mais sólido, a Argentina está perdendo sua competitividade industrial. Com a liberalização do câmbio, decidida no início dos anos 1990, essa perda de competitividade vai resultar numa desindustrialização acentuada até 2003.

Desde 1995 e até 2003 , observa-se um "distanciamento" entre a evolução do salário e a da produtividade. Tal "distanciamento" explica-se essencialmente pelos efeitos conjugados da dupla globalização financeira e comercial, e particularmente pelo modo como ela foi conduzida. De 2003 até 2006, o aumento do salário real foi um pouco mais rápido do que o da produtividade do trabalho (aproximadamente na proporção de $23 \%$ contra $10 \%$ no período mencionado). A diminuição da distância entre as taxas de crescimento do salário real e da produtividade explica-se, ao mesmo tempo, pela retomada da atividade industrial e pelas negociações salariais nos respectivos ramos, sob a impulsão do governo, num contexto de restrições, externa e interna, que os excedentes da balança comercial e do orçamento primário tornaram mais leves.

\section{$O$ aumento relativo dos empregos formais}

De acordo com os trabalhos de Arakaki \& Del Pilar (2009), relativos a 28 aglomerações urbanas, no segundo semestre de 2003, 30\% dos trabalhadores estavam em microempresas (nas quais dominam amplamente os empregos informais), $40 \%$ nas pequenas e médias empresas, e 30\% em grandes empresas (nas quais, ao contrário, dominam os empregos formais). Três anos depois, mudou a estrutura do emprego de acordo com a dimensão da empresa, isto é, 27\%, 40\% e 33\%, respectivamente. As grandes empresas empregam uma parte maior dos trabalhadores e é nelas que os postos informais são em número menor. O peso das microempresas, em que dominam os empregos informais geralmente pouco qualificados, recua. Portanto, em termos relativos, há uma queda dos empregos informais. O emprego, na sua totalidade, progrediu $43 \%$ no período. Segundo os autores, a progressão se deve, por um lado, ao aumento absoluto de empregos informais (23\%), e, por outro lado, à criação de empregos formais (77\%).

Conforme os setores de atividade, a situação não é a mesma. Na indústria, a parte proporcional dos trabalhadores informais é menor do que nos setores da construção civil e do comércio, incluindo as microempresas. A totalidade de 
empregos na indústria aumentou 48\%, e 98\% dessa progressão tem sua explicação na criação de mais empregos formais. É diferente na construção civil, onde a progressão do número de empregados foi de mais de 120\%, mas, no caso, só $35,5 \%$ desses são empregos formais. No comércio, a progressão do número total de empregos foi de $40 \%$, dos quais $75,5 \%$ são empregos formais. A evolução das disparidades salariais não é a mesma - depende dos setores.

Entre 2003 e 2006, o salário mensal médio dos trabalhadores registrados (formais) passou de 904 para 1.372 pesos, ou seja, um aumento de 52\%. Para os trabalhadores não registrados (informais), passou de 493 pesos para 755 pesos, ou seja, um aumento de 53\% (Quadro 1). O leque salarial (entre empregos formais e informais), durante esse período, tende a se manter.

Em geral, os assalariados das grandes empresas ganham mais do que os das pequenas ou médias com qualificação equivalente, e estes últimos, por sua vez, ganham mais que aqueles empregados nas microempresas. Os assalariados com empregos informais ganham mais quando trabalham nas grandes empresas do que aqueles, com nível equivalente, que trabalham nas microempresas, mas a progressão de sua renda é menos expressiva no que diz respeito ao período mencionado ( $26 \%$ contra $56 \%$ nas microempresas).

Ao todo, a disparidade salarial entre os empregos formais e não formais tende a se manter no período em questão e a forte progressão da média dos salários se explica, em parte, pela transformação da natureza dos empregos que evoluem para maior formalidade. À luz dos dados menos completos que os utilizados para o período 2003-2006, pode-se dizer que, apesar da crise de 2009, essas características se mantêm entre 2007 e 2010.

Quadro l - Evolução do salário real conforme o tamanho das empresas e a natureza dos empregos, 2003-2006

\begin{tabular}{l|c|c|c|c}
\hline & $2^{\circ}$ trim. 2003 & $2^{\circ}$ trim. 2004 & $2^{\circ}$ trim. 2005 & $2^{\circ}$ trim. 2006 \\
\hline Total & 736.5 & 782.6 & 939.5 & 1154.1 \\
\hline Formais & 904 & 942.6 & 1123.3 & 1372.3 \\
\hline Informais & 492.6 & 527.2 & 617.7 & 754.8 \\
\hline Microempresas & 476 & 522.2 & 643.8 & 721.1 \\
\hline Formais & 646.9 & 716.1 & 911 & 1038.7 \\
\hline Informais & 399.5 & 433.1 & 510 & 624.7 \\
\hline Pequenas e & 683.5 & 741 & 877 & 1073 \\
médias empresas & 781.3 & 837.7 & 986.5 & 1189.3 \\
\hline Formais & 532.4 & 571.9 & 681.2 & 857.9 \\
\hline Informais & 1958.2 & 1078.2 & 1264.7 & 1568.8 \\
\hline Grandes empresas & 1101.2 & 1114.1 & 1311.8 & 1633.1 \\
\hline Formais & 802.8 & 838.2 & 901.3 & 1008 \\
\hline Informais & & & & \\
\hline
\end{tabular}

Fonte: Arakaki et al. (2009, p.10, de acordo com os dados do EPH). 


\section{O circulo virtuoso do crescimento ameaçado pelo retorno da inflação \\ O crescimento que se tornou virtuoso}

O círculo vicioso, analisado em seu tempo por Diamand e no qual se encontravam numerosos países como a Argentina, tem tendência então a se tornar virtuoso.

Desde 2003 - à exceção do ano 2009 -, a taxa de crescimento é elevada, regular, e vem acompanhada de excedentes da balança comercial que se devem à combinação de vários fatores.

- Com o forte crescimento da China e da Índia, o contexto mundial se modificou. A alta da cotação das commodities, provocada pela demanda desses países, suavizou as restrições (externa e interna) da Argentina, de forma sustentável, graças aos excedentes da balança comercial e à arrecadação fiscal proveniente das exportações de commodities.

- Alguns setores da indústria alcançaram níveis de produtividade próximos daqueles dos países desenvolvidos, o que os capacita a aproveitar uma taxa de câmbio depreciada para exportar mais.

- Enfim, a política seguida pelo governo se assemelha a uma política de taxas de câmbio múltiplas, visando manter uma taxa de câmbio depreciada.

Essa última favorece a indústria, proporcionando-lhe um protecionismo por meio dos câmbios, tornando mais difíceis as importações e facilitando-lhe as exportações. As taxas ("retenciones"), calculadas sobre o preço internacional das exportações de commodities, reduzem os rendimentos dos exportadores em moeda local. Para eles, tais efeitos se assemelham aos de uma valorização da taxa de câmbio. A inflação importada, induzida pela manutenção da depreciação da moeda local e a alta das commodities, dentre as quais os gêneros alimentícios e a energia, pode ser contida por meio de subvenções financiadas pelos recursos provenientes das "retenciones".

Então, o círculo vicioso torna-se virtuoso graças às modificações do contexto, tanto o nacional quanto o internacional: crescimento forte, melhora do emprego e dos salários e, no lugar dos déficits gêmeos, externo e interno, excedentes da balança comercial e excedente primário do orçamento (fora as despesas ligadas ao serviço da dívida). É esse círculo virtuoso que funciona desde o fim do plano de conversibilidade. Entretanto, a recente retomada da inflação, a partir de 2007, ameaça transformá-lo em círculo vicioso nos anos futuros. Não há como explicá-la tão somente pela manutenção de uma taxa de câmbio depreciada. A heterogeneidade da estrutura industrial - apesar de uma certa modernização a partir de 2003 -, as novas formas do conflito distributivo salário-lucro com os assalariados, aumentando seu poder de negociar nessa fase de continuidade do crescimento econômico (Amico \& Fiorito, 2010), explicam também a aceleração da alta dos preços. 


\section{Um retorno preocupante da inflação}

É abundante a literatura sobre a inflação e suas causas. As correntes neoclássicas e monetaristas insistem no excesso da procura em relação à oferta, excesso em razão das despesas públicas exageradas, de rendimentos de trabalho desmedidos, excessos esses que seria necessário conter. As abordagens keynesianas e marxistas, que examinaremos aqui, insistem sobre as condições da oferta e o conflito distributivo. Segundo elas, a sociedade é hierarquizada: os empresários atuam sobre dois mercados, o dos bens, em que fixam os preços, e o do mercado do trabalho, no qual compram a força de trabalho. Quanto aos assalariados, eles atuam sobre um só mercado, o do trabalho. No mercado monopolístico, os preços são determinados pelas empresas. Portanto, a oferta vem primeiro (mais precisamente, o investimento), a procura, em seguida. Depois, sim, o mercado pode corrigir esses preços se a procura for insuficiente, ou abundante demais, em relação à oferta. Assim, a fixação dos preços reflete a estratégia das empresas: depende de seu poder monopolista e tem como objetivo reforçar esse poder em determinados horizontes temporais, pelo investimento permitido pela taxa de margem procurada. Nessa abordagem kaleckiana, a taxa de inflação exprime a divergência entre a necessidade de obter uma certa taxa de investimento correspondente ao montante de investimento desejado pelos empresários e a taxa de salário real que devem pagar aos assalariados. Por sua vez, a taxa de inflação exprime a divergência entre o salário real existente de fato e aquele desejado pelos assalariados. O papel da inflação é, dessa forma, tornar compatível ex-post a distribuição dos rendimentos que não permitia ex-ante o equilíbrio no mercado dos bens.

Choques externos podem agir sobre a taxa de inflação, dar um novo impulso ao conflito distributivo e até mesmo fomentá-lo. A alta da cotação das commodities é um fator inflacionista: tanto a dos produtos agrícolas, que age com mais força sobre o poder aquisitivo das categorias modestas, na medida em que sua cesta básica inclui uma parte importante de produtos de subsistência, como a dos produtos energéticos que se difunde na atividade industrial e nos transportes (a não ser que esses sejam amplamente subvencionados). Foi o caso nos anos 2000. Uma taxa de câmbio que permanece depreciada constitui um canal particularmente favorável à difusão da inflação importada. Ainda que possa servir para proteger a indústria, isto é favorecer, como um todo, a competitividade e a rentabilidade de vários de seus setores, essa taxa de câmbio depreciada também permite que a alta da cotação das commodities se espalhe pelo mercado interno e ampute o poder aquisitivo dos assalariados, ${ }^{4}$ dando início a um novo conflito distributivo e alimentando a inflação, no momento em que os assalariados conseguem recuperar as perdas de seu poder aquisitivo.

De modo mais concreto e à luz do que acabou de ser anunciado, observa-se que, até maio de 2008, o índice dos preços e o índice dos preços dos produtos "comercializáveis" 5 evoluem paralelamente (Gráfico 2). Uma parte da 
alta dos preços pode ser atribuída à inflação importada e essa parte parece não ter variado até maio de $2008 .{ }^{6} \mathrm{O}$ distanciamento entre as evoluções dos dois índices se acentua até janeiro de 2009, diminui fortemente, e depois amplia-se novamente a partir de setembro de 2009. É preocupante a divergência entre os dois índices. A política de câmbio não pode explicar por inteiro a aceleração da alta dos preços, ainda mais porque a taxa de câmbio real começa a valorizar-se a partir de 2011. Essa valorização do câmbio real deveria ser deflacionista. Ora, a inflação cresce, apesar das fortes subvenções alocadas aos transportes e à energia. Entre janeiro de 2009 e janeiro de 2010, a inflação em pesos é de $12 \%$, quando os preços dos produtos expressos em dólares ficam relativamente estáveis. A impressão que se tem é que se a inflação se desenvolve é porque a estrutura industrial continua ainda muito heterogênea, e em parte arcaica, apesar de ter ocorrido uma dupla alta: a da taxa de investimento e a da produtividade do trabalho. Diante de uma procura crescente, a oferta não consegue responder com a rapidez adequada. Portanto, é do lado da oferta e não do lado da procura, em direção a um aprofundamento da modernização da estrutura industrial, que é preciso escolher os remédios a uma inflação demasiadamente alta.

A um só tempo, são a insuficiente modernização do parque industrial da Argentina e, sobretudo, a ausência de numerosos segmentos das linhas de produção, destruídos pela desindustrialização dos anos 1980 e 1990, que explicam que, apesar de uma melhora de sua competitividade média, continue o déficit da balança comercial dos produtos industriais. É isso que vamos analisar.

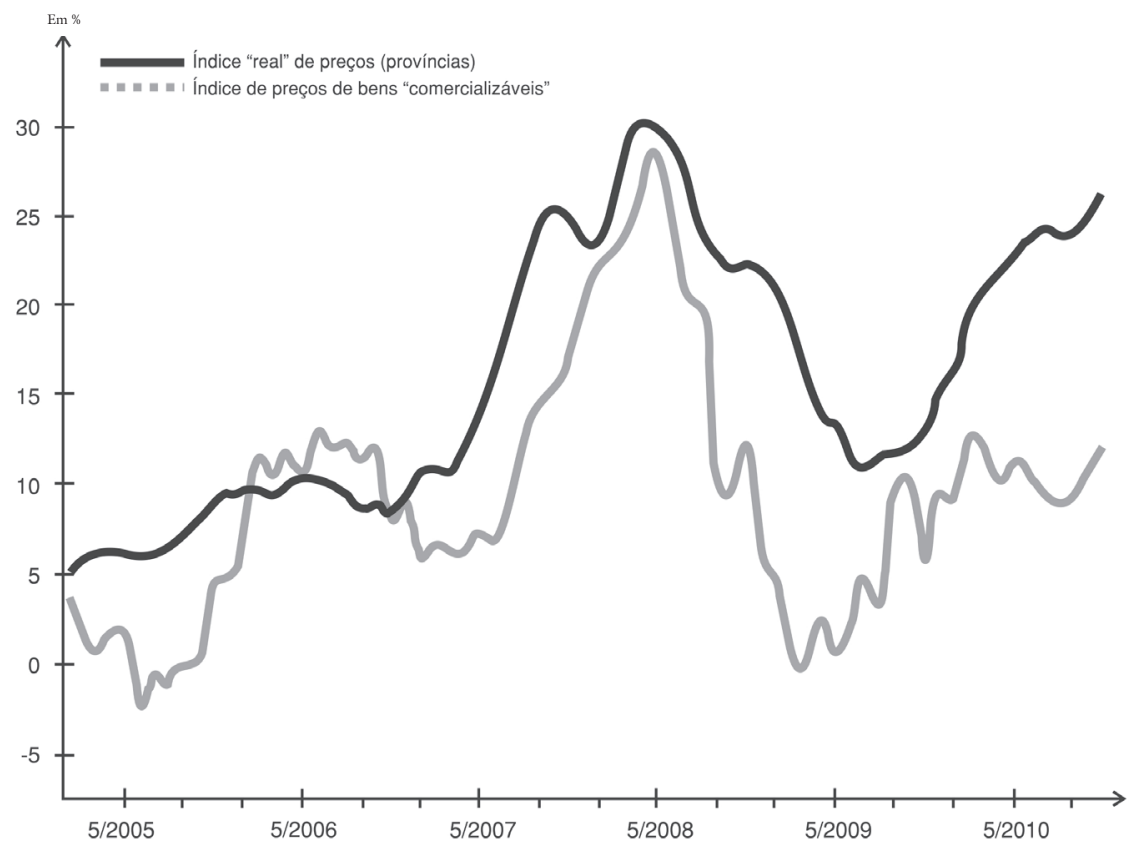

Fonte: Gráfico construído pelo grupo “Inflacionheteredoxa” (2011).

Disponível em: <http://inflacion-heterodoxa.blogspot.com>.

Gráfico 2 - Evoluções dos índices de preços. 


\section{Competitividade e balança comercial da indústria}

Apesar da sensível modernização de alguns ramos do setor industrial, esse permanece profundamente heterogêneo em termos de produtividade. Isso explica em parte que, apesar da melhora da produtividade média e de uma taxa de câmbio favorável, as trocas de produtos industriais com o Brasil continuem deficitárias.

- Mede-se geralmente a competitividade de um país, fora o setor de renda, pelo custo unitário do trabalho, isto é, pela relação salário/produtividade. Basta que o diferencial de salários entre o país exportador e o país importador seja inferior ao diferencial de produtividade para que a competitividade-preço seja favorável para determinada taxa de câmbio. Uma depreciação da taxa de câmbio melhora mecanicamente a competitividade-preço para determinado custo unitário do trabalho. Por outro lado, ao tornar as importações mais caras, a depreciação da moeda nacional protege setores inteiros da indústria, favorece uma integração mais importante das linhas de produção e aumenta o valor agregado dessas. Nesse sentido, a depreciação facilita um adensamento da malha industrial.

- Apesar da evolução do custo unitário do trabalho, da forte desvalorização e da manutenção de uma taxa de câmbio depreciada, a balança comercial dos produtos industriais da Argentina é negativa, inclusive em relação ao Brasil.Com a saída do plano de conversibilidade, no final de 2011, o custo por hora do trabalho, na indústria, expresso em dólares, sofreu uma forte queda. Segundo Abramovitch et al. (2011), o custo por hora de trabalho na Argentina, expresso em dólares, era equivalente a 31\% daquele mesmo custo nos Estados Unidos em 2001. Já em 2002, depois da desvalorização, não passa de $11 \%$. Só recupera o nível anterior à desvalorização, ou seja, 31\%, em 2008. As mesmas tendências aparecem na comparação com o Brasil.

Os Gráficos 3 e 4 mostram que, em 2002, na Argentina, o custo unitário do trabalho em dólares diminuiu consideravelmente, mais do que no Brasil, e em seguida aumenta menos na Argentina do que no Brasil. Pode-se observar que o índice da taxa de câmbio real ponderada pelo custo unitário do trabalho entre esses dois países fica relativamente estável entre 2003 e 2008. Como o fazem notar Abramovitch et al. (2011, p.10), tal estabilidade relativa não se deve à estagnação dos salários na Argentina, visto que esses crescem 38,7\% entre 2001 e 2010. Portanto, o diferencial de crescimento dos salários entre os dois países é compensado pelo da produtividade e pela apreciação do real em relação ao peso.

Aparentemente, a situação não se deteriorou do ponto de vista da competitividade. Entretanto, desde 2003, o saldo comercial entre os dois países se inverte. De 1994 até 2002, as trocas comerciais entre Argentina e Brasil são superavitárias para a Argentina, mas desde 2003 até 2011, tornaram-se deficitárias 
(Iedi, 2011). É um paradoxo. A evolução do custo unitário do trabalho ponderado pela taxa de câmbio não deveria conduzir a esse resultado.

Tal evolução se explica principalmente ${ }^{8}$ pela forte desindustrialização que conheceu a Argentina de 1976 até 2003. A malha industrial argentina é menos densa que a do Brasil. Apesar de uma reindustrialização e modernização da Argentina desde 2003 e da tendência à desindustrialização no Brasil, a estrutura industrial argentina não tem capacidade para resistir de forma eficaz. ${ }^{9}$ Em numerosos setores, a elasticidade da oferta em relação aos preços é mínima. Daí a dificuldade para exportar. A elasticidade de sua procura em relação aos preços não é diferente. Daí uma propensão a importar mesmo com preços em alta.

Quadro 2 - Custos unitários do trabalho comparados na Argentina, nos Estados Unidos e no Brasil

\begin{tabular}{|c|c|c|c|c|c|c|c|}
\hline \multirow[b]{2}{*}{ Pays } & \multicolumn{2}{|c|}{2001} & \multicolumn{2}{|c|}{2002} & \multicolumn{2}{|c|}{2008} & \multirow{2}{*}{$\begin{array}{c}\text { 2001-08 } \\
\text { Variação } \\
\text { Índice relativo }\end{array}$} \\
\hline & Dol.US & $\begin{array}{l}\text { Índice } \\
\text { relativo }\end{array}$ & Dol.US & $\begin{array}{l}\text { Índice } \\
\text { relativo }\end{array}$ & Dol.US & $\begin{array}{l}\text { Índice } \\
\text { relativo }\end{array}$ & \\
\hline Argentina & 8,15 & 1,00 & 2,98 & 1,00 & 9,89 & 1,00 & $0 \%$ \\
\hline Estados-Unidos & 25,9 & 0,31 & 27,01 & 0,11 & 32,26 & 0,31 & $-3 \%$ \\
\hline Brasil & 3,6 & 2,26 & 3,07 & 0,97 & 8,28 & 1,19 & $-47 \%$ \\
\hline
\end{tabular}

(1) O índice relativo é o quociente entre o custo horário do trabalho argentino e o de outro país. Fonte: Abramovitch et al. (2011).

Argentina

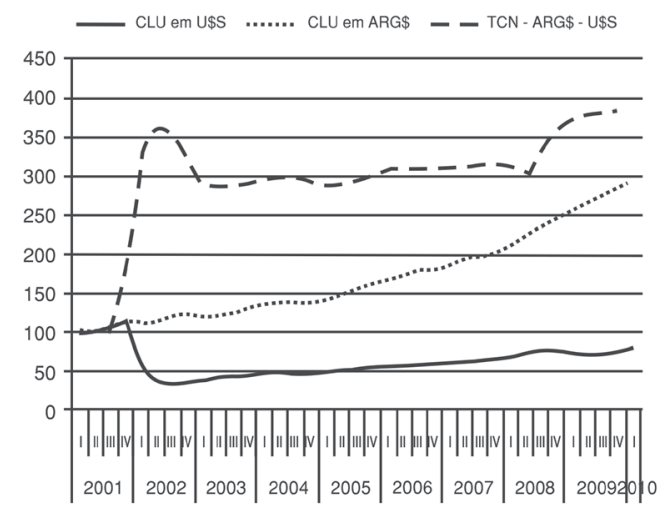

Brasil

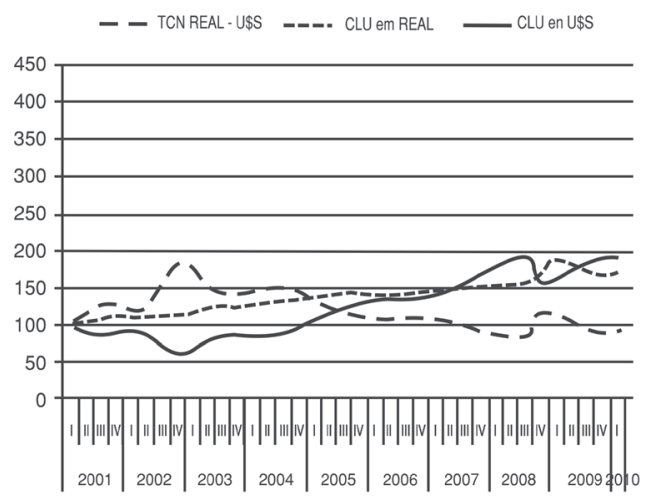

Fonte: Abramovitch et al. (2011, p.10), elaboração dos autores a partir dos dados oficiais.

Gráfico 3 - Evolução do custo unitário do trabalho (CLU) avaliado em dólares correntes.

Assim, durante o período 1994-2009, observou-se que, para 1\% de crescimento do PIB da Argentina, as importações provenientes do Brasil variam de $4 \% .{ }^{10}$

A heterogeneidade da estrutura industrial é uma fonte de inflação pelos custos. Portanto, é para a malha industrial que devem ser direcionados os esfor- 
ços, visando à modernização sem esquecer o valor agregado. Embora a situação externa da Argentina não seja inquietante, ela preocupa. O saldo negativo da balança comercial dos produtos industriais, mais particularmente com o Brasil, constitui um sinal importante da fragilidade da Argentina.

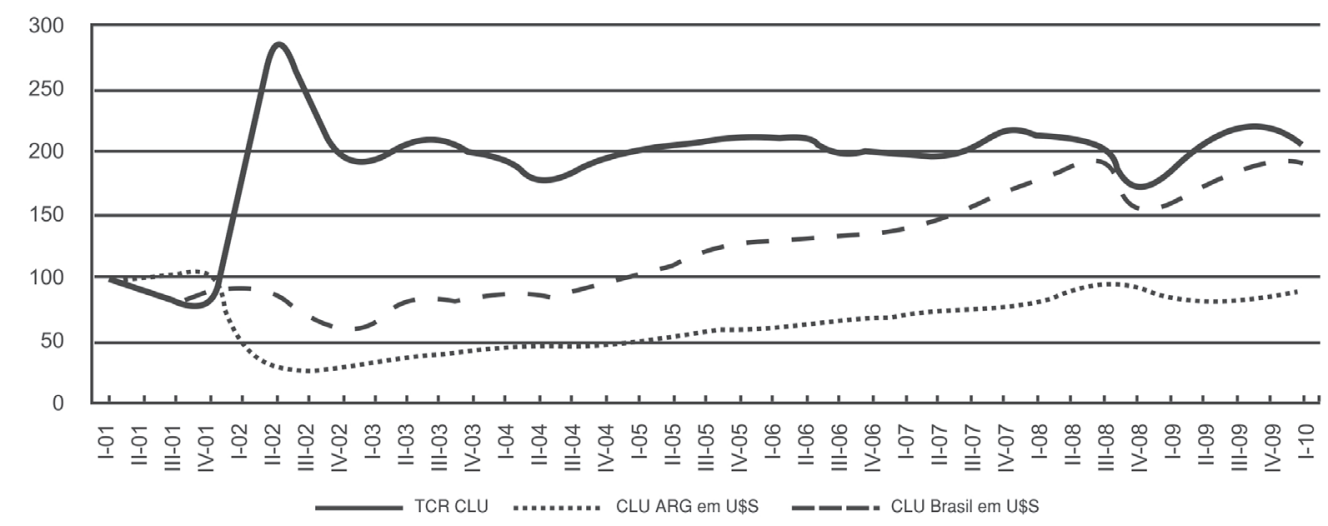

Fonte: Abramovitch et al. (2011, p.10).

Gráfico 4 - Índice de câmbio real bilateral Argentina-Brasil (TCR base 100 em 2001) deflacionado pelos respectivos custos unitários do trabalho (CLU).

\section{Conclusão}

A taxa de crescimento do PIB é muito elevada, o poder aquisitivo dos assalariados está em alta; mesmo quando corrigido por um índice dos preços mais confiável, a situação do emprego melhora, até mesmo no setor industrial, mas em ritmo moderado. A pobreza recua, mas a forte inflação limita a progressão do poder aquisitivo das categorias mais vulneráveis. Os empregos informais, assalariados ou não, perdem sua importância relativa, a balança comercial é nitidamente superavitária, a taxa de endividamento não é excessivamente elevada e pode-se esperar que, num futuro próximo, a Argentina se relacione novamente com os mercados financeiros internacionais. Enfim, as reservas internacionais aumentam, apesar das saídas maciças de capitais em 2008 e 2009.

A recente apreciação da taxa de câmbio real, a quase inexistência de uma política comercial com metas definidas e, finalmente, uma estrutura do sistema fiscal que continua amplamente regressiva ${ }^{11}$ são aspectos próprios a fragilizar o modelo argentino. Entretanto, a não ser no caso de um choque provocado por nova crise internacional e a queda da cotação das commodities, o círculo virtuoso que beneficia a Argentina deve vigorar em curto e em médio prazos, embora perdendo parte de seu dinamismo.

Uma das causas da reindustrialização da Argentina tem suas raízes na política de câmbio escolhida, a qual se assemelha de facto a uma política de taxas de câmbio múltiplas. Apesar da apreciação recente da taxa de câmbio, essa continua relativamente depreciada. Uma taxa como essa protege a indústria, favorece 
uma nova substituição das importações e permite uma alta dos salários reais sem que essa alta tenha necessariamente um impacto significativo sobre os salários expressos em dólares. A combinação da alta dos salários e do emprego tem efeitos positivos no crescimento econômico enquanto o saldo da balança comercial permanece positivo. As taxas ("retenciones") sobre as cotações das commodities são equivalentes a uma taxa de câmbio apreciada para os exportadores de commodities, uma vez que cada dólar obtido é convertido em menor número de pesos. Essas taxas alimentam o orçamento e permitem livrar-se de suas exigências. Uma vez removidas as restrições, externa (saldo da balança comercial) e interna (excedentes primários no lugar de déficit), o prosseguimento do crescimento econômico encontra menos obstáculos e pode se realizar em ritmo vigoroso, desde que não se apresente uma retomada da inflação.

Hoje, a aceleração da alta dos preços põe em perigo o modelo argentino. Por isso, é provável que, depois de reeleita, a presidente opte ao mesmo tempo por: 1. uma política de contenção da procura global, em vez de tentar desenvolver a oferta estimulando o investimento no setor industrial e nas infraestruturas (energia, transporte), no intuito de frear a alta dos preços. Agir sobre a procura global pode reduzir a taxa de inflação, mas à custa de uma desacelaração da atividade econômica; 2. uma economia cada vez mais administrada (controle de determinados preços, volta a medidas protecionistas inclusive para com países membros do Mercosul, estatização de grandes empresas que investem insuficientemente), própria a resolver alguns problemas econômicos imediatos, com forte probabilidade de ampliar o processo de fuga de capitais, já considerável. Num contexto de desacelaração da economia mundial, haveria então grande risco de o "milagre" argentino desaparecer.

\section{Notas}

l O índice do nível de emprego passa de 100 em 2001 para 94 em 2002, para depois subir rapidamente e atingir 118 em 2007. O salário real médio é de 100 em 2001, passa a 75 em 2002; 72 em 2003; para, em 2007, quase reencontrar seu nível de 2001 (Fonte: Ministério da Economia da Nação). Entretanto, convém observar que, nos últimos anos, a criação de empregos se dá num ritmo mais lento: dos três milhões de empregos criados entre 2003 e $2010,80 \%$ o foram entre 2003 e 2007 . O setor público ofereceu mais vagas (4\% em média por ano) do que o setor privado $(2,7 \%)$. Em 2009, ano de crise, o emprego público aumentou, enquanto o privado diminuiu.

2 Convém lembrar que, com a explosão do plano de conversibilidade, o sistema financeiro desabou. Assim, autofinanciamento e disponibilização de recursos "escondidos" foram as únicas fontes a garantir o sucesso do investimento.

3 Em 2006, diante da alta desmesurada dos preços, as autoridades públicas modificaram a composição do índice dos preços (Indec). O novo índice subestima a taxa de inflação. A credibilidade do índice e dos dados divulgados pelo governo baixou. A subestimação da inflação conduz "mecanicamente" a sobreestimar a uma só vez a taxa de crescimento calculada a preço constante e a parte que cabe aos salários no cálculo do 
“valor agregado" a partir de 2007. Os índices calculados pelas províncias não foram modificados. Frequentemente, eles são utilizados como base para avaliar a "verdadeira" alta dos preços. Existem outros índices fornecidos por universidades, sociedades privadas. Geralmente, essas sociedades não têm os meios para construir o índice (coleta de dados insuficiente) e a construção de seu índice é habitualmente opaca. Muitas vezes opostas à política do governo, elas tendem à sobreestimar a taxa de inflação. Preferimos aqui levar em consideração o índice composto a partir daqueles fornecidos por províncias que não modificaram a metodologia do índice a nos basear numa média de dois índices, o do Indec e o das sociedades mencionadas.

4 Muitas vezes, os produtores abastecem de produtos alimentares tanto o mercado interno quanto o externo. Por isso, têm tendência a igualar os preços do mercado interno com os preços obtidos por eles no mercado externo.

5 O índice do nível geral dos preços aqui utilizado não é o do Indec, pelas razões indicadas anteriormente. Ele é, na realidade, um índice sintético, concebido a partir dos índices das diferentes províncias, os quais não foram reconstruídos (ver nota 4). O índice dos produtos "comercializáveis" é um índice estabelecido a partir dos preços internacionais (média entre os preços das exportações e os das importações argentinas) avaliados em conformidade com a taxa de câmbio vigente. Ele constitui um bom indicador da inflação importada.

6 O índice dos preços dos produtos "comercializáveis" não repercute integralmente no índice geral dos preços por duas razões, a primeira porque uma parte importante das exportações é constituída por produtos intermediários ou bens de equipamentos que servem para produzir bens; a segunda porque o governo tenta minorar o efeito da alta espetacular de preço dos produtos alimentares e energéticos, subsidiando esses produtos. Em 2008, dos 31 bilhões de pesos de subvenções, 16,2 bilhões eram destinados ao setor energético, 87 ao setor dos transportes e 3,8 ao setor alimentar (Fonte: ASAP in Frenkel \& Damill, 2009, p.64. Ver também Salama (2008).

7 Dois fatores explicam essa nova subida: uma ligeira revalorização do peso frente ao dólar e um aumento dos salários reais superior àquele observado nos Estados Unidos.

8 Não podemos tratar aqui, neste artigo, dos comportamentos diferentes dos industriais em relação às taxas de margem desejadas. É provável que o déficit comercial se explique também parcialmente pelas consequências de um acesso ao crédito menos frequente na Argentina do que no Brasil. A taxa de margem, bastante procurada na época para financiar os investimentos, poderia ser maior na Argentina do que no Brasil. Disso resultaria uma alta relativa dos preços que teria um impacto negativo sobre a competitividade. Da mesma forma, o contexto, mais inflacionista na Argentina do que no Brasil, poderia alimentar antecipações inflacionistas e minar a competitividade-preço.

9 O déficit da balança comercial dos produtos industriais não deve ocultar um forte crescimento das exportações desses mesmos produtos. Tomando como base $100 \mathrm{o}$ ano 1993, as exportações de Manufaturados de Origem Industrial (MOI) alcançam, no quarto semestre de 2010,733,6 em valor e 587,9 em volume, e as de origem agrícola, 517,7 e 297,5, respectivamente (Indec, 2011). No conjunto, as perspectivas para 2011 são excelentes com uma alta das exportações de $17 \%$ com relação a 2010: o seu total deveria alcançar 81 bilhões de dólares, isto é, o dobro do montante em valor alcançado em 2005 e o triplo daquele de 2001. As importações deveriam progredir vigorosamente, $28 \%$ provavelmente, em 2011 , em razão do crescimento acentuado e da valorização 
do peso. A amplitude dos excedentes da balança comercial será provavelmente reduzida, mas deve permanecer em nível confortável (2\% do PIB, 3 de janeiro de 2011).

10 Ver Indec (2009). Segundo o Indec, a estrutura das exportações da Argentina à destinação do Brasil é a seguinte: $33 \%$ de produtos alimentares, $32 \%$ de produtos industriais, $25 \%$ de produtos primários, e $10 \%$ de combustíveis, e $42 \%$ das exportações industriais da Argentina são destinadas ao Brasil. O peso da indústria automobilística é muito importante, já que $81 \%$ das exportações de automóveis e $65 \%$ das de autopeças vão para o Brasil. A estrutura das importações da Argentina provenientes do Brasil é a seguinte: 19\% de maquinas, 30\% de equipamentos, 19\% de autopeças, $10 \%$ de automóveis, $12 \%$ de artigos de consumo e 11\% de combustíveis. Segundo Gigliani \& Perrone (2004, p.4), o total das exportações industriais da Argentina reunidas na rubrica Manufaturados de Origem Industrial (MOI) triplicou entre 2002 e 2008, e as destinadas ao Brasil, um pouco mais (três vezes e meia), mas as importações provenientes desse país foram multiplicadas por 7,5. O essencial desse déficit com o Brasil se explica pelas compras de máquinas, aparelhos e materiais elétricos.

11 Não podemos tratar aqui dessa questão muito importante. Para a Argentina, ver Gagerro (2008), Gomez \& Rossignoo (2008) e Goni et al. (2008).

\section{Referências}

ABRAMOVICH, A. L. et al. Dynamica salarial y tipo de cambio real, un analisis exploratorio de los costos laborales relativos de la industria argentina y sus principales socios comerciales en el periodo 2001-2010. In: $2^{\circ}$ CONGRESSO ANUAL ARDA. Lineamentos para un cambio estructural de la economia argentina. Desafios del bicentenário. 2011, p.1-23. (Mimeog.)

AMICO, F.; FIORITO, A. Exchange rate policy, distributive conflict and structural heterogeneity. The Argentinean and Brazilian cases. In: Atas do Colóquio Sraffa. 2010. p.1-26. Available in: <http://grupolujan-circus.blogspot.com>.

ARAKAKI, G. A.; DEL PILAR, P. La disparidad salarial: una cuestión includible para discutir el modelo de crecimiento en la Argentina de la post-convertibildad. CEPED-IIE-UBA, 2009. (Mimeog.)

CEPAL - Comisión Económica para América Latina y el Caribe. Anuario estadístico. Santiago de Chile: Cepal, 2010.

CRUZES, G.; GASPARINI, L. Desigualidad en Argentina, una revisión de la evidencia empírica. Desarrollo Economico, $1^{a}$ parte, v.48, n.192, p.395-437, 2009; $2^{\text {a }}$ parte, v.49, n.193, p.3-29, 2009.

DIAMAND, M. El pendulo argentino: hasta cuando? Revista Circus, 2011. Disponible in: <http://grupolujan-circus.blogspot.com>.

FRENKEL, R.; DAMILL, M. Las politicas macroeconomicas en la evolución reciente de la economia argentina, Nuevos Documentos Cedes, n.65, p.1-89, 2009.

GAGERRO J. La progressividad tributaria: su origen, apogee y extravio. Documento de Trabalho, n.23 CEFID*AR, 2008.

GIGLIANI, G.; PERRONE, G. Argentina, peso devaluado y agravamento del deficit industrial, 2002-2008. In: III $^{\circ}$ JORNADAS DE ECONOMIA POLITICA, 2009, p.116. 
GOMEZ, S.; ROSSIGNOO, D. Argentina, analisis de la situación tributaria y propuestas de reformas impositivas destinadas a mejorar la distribución del ingresso, Working Paper, Universidad de Buenos Aires, 2008.

GONI, E. et al. Fiscal redistributión and income inequality in Latin America. Policy Research Working Paper, n.4487, 2008.

IEDI. Argentina, Brasil e o Mercosul. Brasil, 2011.

INDEC. Comercio Argentina-Brasil, una perspectiva desagregada, nota técnica n.15, 2009, p.1-8.

2011.

Ministerio de economia y finanzas publicas. Comercio exterior, Argentina,

LINDENBOIM, J. et al. El debate sobre la distribución functional del ingresso. Desarrollo Economico, v.49, n.196, p.541-71, 2010.

LO VUOLO. Distribución y crescimiento, una controversia persistente. S. 1.: Mino y Davila, 2010.

SALAMA, P. Le défi des inégalités; Amérique latine/Asie, une comparaison économique. Paris: La Découverte, 2006.

Argentine: la hausse des matières premières agricoles, une aubaine? 2008, p.1-

25. Comercio Exterior, p.836-51, 2009.

RESUMO - Desde 2003, a taxa de crescimento do PIB foi mais elevada na Argentina do que no Brasil, e a distribuição da renda, menos desigual. Diminuiu a pobreza. Aumentou o emprego - incluindo o setor industrial - e os empregos informais, assalariados ou não, perdem sua importância relativa. A balança comercial é fortemente superavitária, a taxa de endividamento não excessivamente elevada. A inflação real tem nível elevado, muito mais forte do que aquela anunciada pelo governo e reduz o poder aquisitivo entre as categorias mais pobres. $\mathrm{O}$ apreciamento recente da taxa de câmbio efetiva, $\mathrm{o}$ peso crescente das commodities nas exportações, das quais depende o financiamento das subvenções concedidas particularmente aos setores com forte consumo de energia, os subsídios insuficientes destinados às indústrias intensivas envolvidas com pesquisa podem transformar o círculo virtuoso de hoje num círculo vicioso amanhã.

PALAVRAS-CHAVE: Industrialização, Inflação, Pobreza, Conflito distributivo, Taxa de câmbio

ABSTRACT - Since 2003, the growth rate of the GDP has been higher in Argentina than in Brazil. Income distribution is less unequal. Poverty has decreased. Employment is growing - including in the industrial sector -; informal jobs, whether salaried or not, are loosing ground; while the balance of trade shows a trade surplus and the debt ratio is not overly right. Real inflation is hight, far higher than announced by the government, and it curtails any rise in buying power, particularly among the poorest. The recent rise ineffective exchange rates, the rise in the share of raw materials in exports, the fact that these are needed for subsidies paid mainly to energy consuming sectors, the shortage 
of subsidies to research intensives industries could to morrow turn what is currently a virtuous circle into a vicious circle.

KEYWORDS: Industrialisation, Inflation, Poverty, Distributional conflicts, Exchange rate.

Pierre Salama é doutor em Economia pela Universidade Paris-Sorbonne, professor da Universidade Paris XIII, membro do Conselho Científico e do Conselho de Relações Internacionais da mesma universidade. É autor de vários livros, entre eles, no Brasil: Pobreza e exploração do trabalho na América Latina (Boitempo, 2002).

@- pierresalama@gmail.com.

Tradução de Jean Marie Joseph Briant. O original em francês - "Croissance et inflation en Argentine sous les mandatures Kirchner" - encontra-se à disposição do leitor no IEA-USP para eventual consulta.

Recebido em 9.7.2011 e aceito em 26.11.2011. 